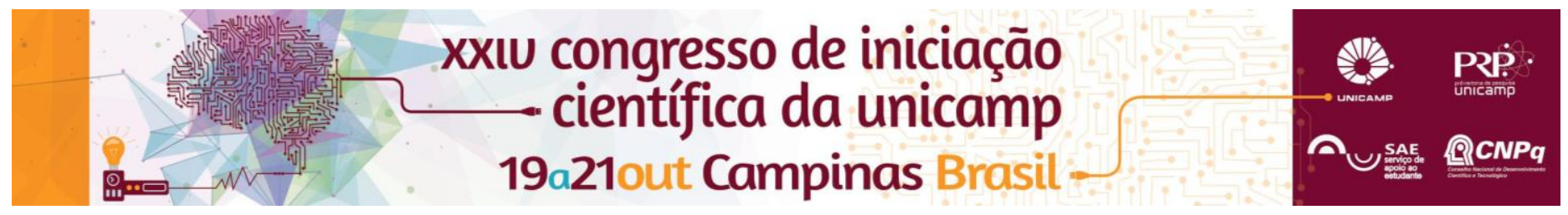

\title{
Avaliação da produção de gases de efeito estufa em um sistema de leitos alagados construidos.
}

\section{Amanda de Camargo*, Raul Lima, Talita F. de Oliveira, Adriano L. Tonetti.}

\section{Resumo}

O projeto foi avaliar a produção de gases de efeito estufa em processo de desnitrificação em Leitos Alagados Construídos (LAC) vegetados e não vegetados. No estudo, a partir da terceira etapa os leitos alagados construídos serão operados com a presença de bactérias anammox. Os resultados mostram que na LAC vegetada a maior remoção de nitrogenio, porém os gases presentes tiverem efeitos não significativos.

\section{Palavras-chave:}

Leitos alagados construidos, desnitrificação, reatores anaeróbios.

\section{Introdução}

Os Leitos Alagados Construídos (LAC) são uma alternativa engenhosa de tratamento de efluentes industriais e domésticos devido à sinergia entre o solo, plantas e os processos físicos, químicos e biológicos realizados por micro-organismo ${ }^{1}$. O uso de LAC pode efetivamente reduzir o impacto de uma carga excessiva de nutrientes, como o nitrogênio, protegendo os mananciais da eutrofização ${ }^{2}$. As rotas de remoção de nitrogênio nos leitos alagados dependem de vários fatores ambientais e operacionais, quanto à desnitrificação, tem chamado à atenção seu potencial de produção de gases de efeito estufa ${ }^{3}$, como o $\mathrm{N}_{2} \mathrm{O}$. O N $\mathrm{N}_{2} \mathrm{O}$ é um gás com impacto significativo no aquecimento global, pois além de intensificar o efeito estufa. Desse modo, o objetivo do trabalho foi avaliar produção de gases de efeito estufa em processo de desnitirificação.

\section{Resultados e Discussão}

A pesquisa foi desenvolvida em unidade piloto de LAC (Figura 1) no qual foi dividida em 3 etapas. $\mathrm{Na}$ etapa I com o efluente do reator anaeróbio (100\%), na etapa II efluente do reator anaeróbio (75\%) mais efluente do filtro de areia (25\%) e por última etapa III efluente do reator anaeróbio $(75 \%)$ mais efluente do filtro de areia (25\%) com o inóculo de anammox. As medições dos gases foram feitas a partir da etapa II.

Figura 1: Sistema de Leitos Alagados Construídos

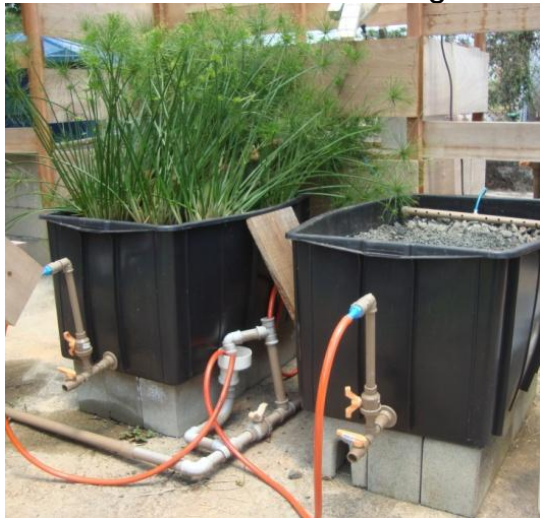

Figura 2: Taxa de remoção média $\left(\mathrm{gN} \mathrm{m}^{2} \mathrm{~d}^{-1}\right)$

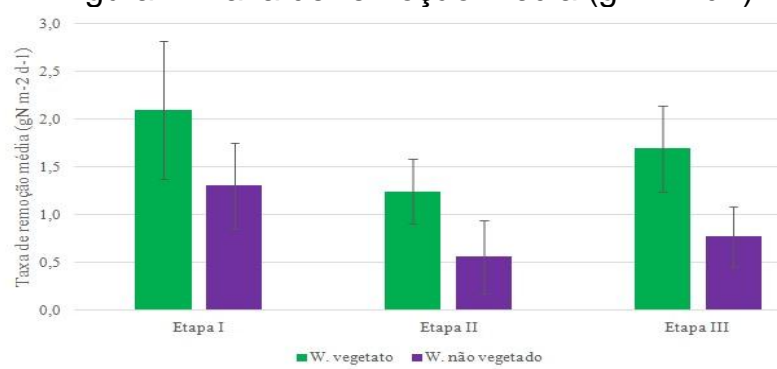

Tabela 1: Composição dos gases e atividade desnitrificante durante a etapa II

\begin{tabular}{|l|c|}
\hline & $\begin{array}{c}\text { Atividade desnitrificante } \\
\left(\mathrm{mgN} \mathrm{kg}^{-1} \mathrm{~d}^{-1}\right)\end{array}$ \\
\hline LAC vegetado & 19,2 \\
\hline LAC não vegetado & 4,1 \\
\hline
\end{tabular}

Os resultados encontrados para a avaliação dos gases de efeito estufa estavam abaixo do nível de detecção da técnica analítica de cromatografia gasosa, sendo assim os resultados não foram significativos.

\section{Conclusões}

A unidade vegetada apresenta maior taxa de remoção de nitrogênio em relação à unidade não vegetada.

Os leitos alagados estão desnitrificando, porém não esta produzindo gases o suficiente, sendo assim na avaliação da produção de gases não houve um valor significativo em relação à remoção total de nitrogênio.

\section{Agradecimentos}

Ao CNPq (Conselho Nacional de Desenvolvimento Científico e Tecnológico), pela concessão da bolsa de Iniciação Científica.

1Vymazal, J., 2009. The use constructed wetlands with horizontal sub-surface flow for various types of wastewater. Ecol. Eng. 35, 1-17.

2SAEED, Tanveer; SUN, Guangzhi. A review on nitrogen and organics removal mechanisms in subsurface flow constructed wetlands: Dependency on environmental parameters, operating conditions and supporting media. Journal Of Environmental Management, v. 112,p.492448, dez. 2012.

3 Wang, Z., Liu, C., Liao, J., Liu, L., Liu, Y., Huang, X., 2004. Nitrogen removal and $\mathrm{N} 2 \mathrm{O}$ emission in subsurface vertical flow constructed wetland treating swine wastewater: Effect of shunt ratio. Ecol. Eng. 73, 446-453. 